\title{
The 'Nearly Digital Natives' of Brunei Darussalam: A Review of Digital Diversity, Nativisation, Wisdom and Dissonance in the Digital World
}

\author{
Pengiran Shaiffadzillah Pengiran Omarali \\ University of Manchester, United Kingdom
}

\begin{abstract}
A 2013 report by the International Telecommunications Union (ITU) ranked Brunei Darussalam $13^{\text {th }}$ out of 180 countries in its Digital Natives list with $73.7 \%$ of the Brunei youth population profiled as digital natives. However, the 'digital nativeness' of Brunei's learners is hardly reflected in their learning; prompting the question if these learners are indeed digital natives. Extending from a preceding literature review that analysed the discourse between proponents and critics of the 'digital native' theory, this paper integrates into the existing discussion several new profiling constructs, notably the constructs of 'digital wisdom', digital dissonance and the digital world. In addition, recent concurrent studies on Bruneian learners' dispositions towards digital nativeness have contributed to a more contextualised understanding of the learner. This review expands its query from identifying two hypotheses on the existence of digital natives in the Brunei learner population, to establishing a further two hypotheses that inform us of the pathways our dynamic learners undertake in seeking digital nativeness.
\end{abstract}

\section{Introduction}

Marc Prensky first coined the term 'digital natives' in 2001 to define a generation of youths who fitted the criteria of being "born after the 1980s surrounded by and immersed in digital technologies such as computers, video games, cell phones and other toys and tools of the digital age" [1]. It is onehalf of his binary 'Digital Native-Digital Immigrant' theory where the digital immigrant is the direct opposite of the aforesaid definition.

At the time, it was an apt terminology to describe these learners based on the simplified logic adopting the concept of 'native speakers' born and immersed into their first language, with the distinction here being that digital natives are all "native speakers of the digital language of computers, video games and the internet" [1].

This simplicity, at times argued by critics of the theory as also being "overly simplistic" [2], [3], [4], allowed the concept to persist today in many education circles among leaders, policy-makers and educators. Confirmation bias based on their subjective observations of learners' fluent use of digital technologies may also lead to an unquestionable belief that learners are indeed digital natives, without considering the digital dissonance that exists between using technology for learning purposes and using technology for social and entertainment purposes [5]. Beyond Prensky's work, the digital natives theory in its first five years did not have a pronounced impact on academic literature with a few fleeting studies at best [6], [7], [8], [9], but regardless 6 years after its introduction it eventually made its way to Brunei.

\section{Brunei and its 'digital natives'}

In 2007, Professor Lee Sing Kong of the National Institute of Education Singapore in his keynote address to the Brunei education community suggested that, "our profile of students has changed. Schools today are admitting 'digital natives' and as digital natives they demand different approaches to learning to stay engaged" [10]. This was one of the first instances that the term digital natives was openly mentioned in Brunei, becoming the in vogue validation towards a nation-wide drive to integrate educational technology into learning.

Based on the perception that "teachers today are the digital immigrants, while the students are the digital natives" [11], a complete education reform was implemented in 2009 called the National Education System for the $21^{\text {st }}$ Century (SPN21), to prepare for $21^{\text {st }}$ century learners who are supposedly predisposed towards learning using, among others, digital pedagogies and technologies [12]. A flagship ICT-in-Education strategic blueprint, called the eHijrah project, was launched in 2010 to respond to this need [13] followed by 49 e-Learning initiatives to be implemented in sequential phases expanding 5 years each. The grand scheme was to equip the education system with the necessary digital pedagogies and technologies to cater for the needs of the digital natives. 
However, in this chronological melée of changes, one element has been crucially absent from the start - the empirical evidence for digital natives. In other words, these changes were based on one hypothesis. It is a widespread oversight as "the idea of the digital native captured the imagination of teachers, parents, journalists, commentators and academics" [14] but one that is substantiated by "anecdotes, conjecture and speculation" [14].

Thus, ever since Prensky's claim, "a significant body of international research has largely debunked the idea of a uniformly technically savvy generation" [14], but still the term has persevered in many education systems through the moral panic generated by the news media [15], Brunei's education system notwithstanding.

\subsection{An updated review on the digital natives}

This literature review is an updated expansion of a preceding literature review reported in the Proceedings of the World Congress on Education 2017 [16]. Revisiting discussions and findings from the previous literature review, this expanded version integrates new concepts to the discourse, in hopes of bridging the discussion from that pertaining to the state and identity of being a digital native, to a broader discussion on the dynamic evolution of learners perpetually seeking digital nativeness.

Therefore, this review is a more in-depth reiteration of the previously established discourse, through integrating the concepts of 'digital wisdom' [17], 'digital dissonance' [5] and the nature of learners and their learning in an increasingly 'digital world' [18], [19]. Integrating these additional facets of the digital learner will provide the policy-makers of Brunei, and possibly of other nations, a more holistic understanding of where our learners stand in the digital native theory.

Another new inclusion to this holistic review is the collection of recent findings from learner profiling studies [20], [21], [22]. These studies, involving Bruneian learners to gauge among others their digital nativeness, provide a contextual representation of the phenomenon in 'practice', which draws from Pierre Bourdieu's work on how behaviour and dispositions are more authentic when observed in practice [23], [24]. Therefore, if indeed the learners are digital natives, how do they exhibit themselves as learners in the digital yet real world?

The aim of this literature review is to formulate several hypotheses regarding the identity of our selfstyled digital natives. If they are, as reported, mainly tech-savvy, then by virtue of design they fulfill the digital natives attribute. The question that serves as the impetus for this review is: Are Bruneian students digital natives?

\section{Review method}

The systematic method by which the body of literature on digital natives was reviewed and the measures that were taken to optimise clarity on the strategies involved in searching and selecting pieces of relevant and valid literature have been extensively presented [16]. The use of keywords, related words, author names and Boolean logic in searching through the Google Scholar, Scopus and ERIC databases in three sequential search phases has also been elaborated in the preceding literature review [16].

To reiterate, the preceding literature review employed the SALSA method (Search, AppraisaL, Synthesise and Analyse) [25], which narrowed the expansive body of literature to 132 academic articles based on an inclusion/exclusion search criteria including but not limited to the degree of relevance, education-related discourse, and peer-reviewed academic articles. These articles were further appraised and synthesised together through a combination of software and applications in a meticulous process described in detail as follows:

The research management software Mendeley was used to first categorise the 132 pieces of literature, and then complemented with a selfcustomised Microsoft Excel database to enable the comparison of data in the following steps, (i) Data extraction via tabulation, (ii) Inclusion and exclusion of literature based on its data content, and (iii) Critical appraisal based on comparing the data content of included literature.

Firstly, for data extraction, the literature was tabulated into three categorised columns based on the general information, the in-depth content, and its relevance to the review. These columns further branched into their respective filterable sub-columns, with each sub-column representing a data set. The filter columns feature allowed the same list to be rearranged based on a particular data and hence illustrated data patterns. Altogether there were 16 filterable sub-columns (SC) referred to as SC.1 to SC. 16

Secondly, the filterable data functioned as an inclusion-exclusion filter, particularly for 'SC.12 View', where literature without a clear stance on the concept was excluded, and 'SC.13 - Field' where fields of study such as pharmacy education or professional development training were filtered out. This process narrowed the literature pool to 120 .

Thirdly, the platform was also used in assessing the quality of each paper through meticulous mapping of relevant data. Citation count was also acknowledged, albeit at face value. This process eventually narrowed down the list to 64 relevant pieces of literature based on overall quality (i.e. High=33, Very High=25, Significant=3, Unique=3).

Within this pool of 64 selected literature, notable contributions outside of Prensky's own work include 
the commentaries of Palfrey and Gasser [26], Selwyn's [27] holistic discussion on the education technology debate, and Bennett, Maton and Kervin's critical opinion on the theory [15]. These studies and commentaries served the basis of the preceding literature review.

In this updated version, the inclusion of digital wisdom, digital dissonance and digital worlds as additional dimensions to profiling the learner were analysed a posteriori to the information synthesised from the above SALSA review method. These concepts underwent their respective scoping search and synthesis based on their relevance to the existing discussion that has previously generated two hypotheses.

Thus, in this extended discussion, the two existing hypotheses established during the preceding literature review are again presented here, and a further two new hypotheses based on digital dissonance and digital wisdom broadens the discourse. Altogether this literature review has formulated four hypotheses.

In addition, several Brunei learner-profiling studies have been performed concurrent to this topic [20][21][22]. Findings from these studies contribute to the discussion where appropriate through providing a context upon which learners' digital nativeness has been observed in practice.

\section{Discussion}

Based on reviewing the 64 selected literature, a pattern of theories, comments and evidence indeed revolve around the digital native concept, but they mainly represent either extremes of the digital native discourse spectrum, viz. the advocates and critics. Interestingly, it was found that there exists a third and rare group of commentators that have taken new stances, floating several steps away from the debate with their different perspectives on the argument.

This review associates itself with this third group and their off-centre perspectives, because any new knowledge of this concept is not derived from partaking in the two-sided debate and counting votes, but from inquisitively inferring subtle notions from the amalgamation of loud and conflicting evidence. These notions are presented as hypotheses that are capable of answering the question.

\subsection{Existence vs. absence}

The main criticism of the digital natives theory is that it is based on conjectures and not empirical evidence. In addition, there has not been any dedicated theory-building study, or at the very least abductive reasoning commentaries to support what is simply speculation. Several studies have proven that digital natives do not exist, or only represents a small group of elites [15], [26], [27], [28]. However, one caveat is that these same studies share a common trait; in that they predominantly focus on young adults. Of the 13 debunking studies included in this review, 8 studies were performed on university students [29][30][31][32][33][34][35][36], 2 on middle and high school students [37][38] and one had its youngest sampling frame as 20 years old and above [39].

Only one study included a younger sample in a range of 12-30 year olds. This study concluded that "when it comes to the generational differences for the Internet activities analysed ... it is shown that very few Internet activities can be ascribed to the Net Generation"' [40]. It obviously refutes the digital native theory.

However, the same study also found that the youngest sample (12-16 year olds), who scored highest in the self-efficacy measurement, possibly "would have scored higher on the Internet skills if they were asked about activities they frequently engaged in" [40].

This forethought is noteworthy, for the few empirical studies that $d o$ provide evidence of digital natives concerned samples of 10-11 year olds [41], 8-19 year olds [42] and 13-16 year olds [43]. When these two bodies of seemingly conflicting evidence are aligned together, an assumption that can be made is that the younger the sample, the higher the chances of encountering digital natives, as illustrated in Figure 1 below:

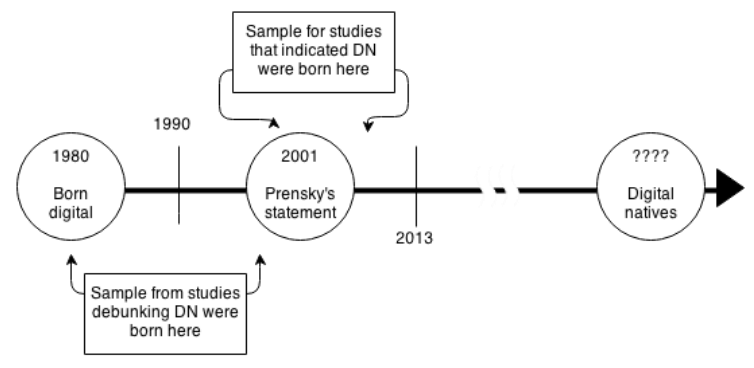

Figure 1. Timeline showing when samples from studies debunking and supporting digital natives (DN) were born

To declare that a generation of digital natives exists, from the basis of this evidence alone, is indeed premature. However, perhaps what is premature is Prensky's theory after all. This review assumes that Prensky forecasted right but targeted the wrong generation, as did the opposition of his theory in countering his claims.

This integration of evidence provides us a new perspective that another variable is dictating the pace of our newfound trend. This extraneous variable that runs parallel with this graphic trend, yet has been made immaterial in the discourse is the development of the Internet.

Taking just two statistics from 2001 to 2013 , the global-mobile cellular usage rose from $15.5 \%$ to 
$96.3 \%$, while the global Internet usage rose from $8 \%$ to $38.8 \%$ [44]. Computer ownership experienced a sharp rise in the 1990s for the United States [45], as was the case for the United Kingdom [46]. This entails that the digital natives, who were assumed to have been immersed in technologies, were rightly a small minority from when technologies were in abundance around these elites.

The digital native concept itself hinges on ICT development, for the digital natives are "born after 1980, when social digital technologies, such as Usenet and bulletin board systems, came online. They all have access to networked digital technologies. And they all have the skills to use those technologies" [26].

However, this timestamp is inaccurate as the World Wide Web only came online on 6 August 1991 and technology usage and ownership only became significant in the mid 1990s [49]. Thus, we arrive to the first hypothesis that more digital natives will exist with increased technology immersion.

\subsection{Homogeneity vs. diversity}

Another prevalent criticism of Prensky's digital native concept is that it suggests a homogeneous group of youth sharing a uniform digital competency. As rephrased by skeptics of this concept, Prensky [1] assumed them to be "a homogeneous group characterized by their wide experience and advanced skills in using information and communication technologies" [36].

In refuting Prensky's claim, Bennett et al. stated that, "it is apparent that there is scant evidence to support this idea, and that emerging research challenges notions of a homogeneous generation with technical expertise and a distinctive learning style" [15]. In addition, Jones et al. found from research that students comprise of "a complex picture of minorities, most of whom engage in a wide range of technology uses with a high frequency but who do not show a strong impulse towards the kind of participation and generational homogeneity predicted by Net generation or Digital Native inspired literature" [34].

We have established the first notion earlier that we expect digital natives to currently exist as the minority. On the account of homogeneity however, we may be content of this to be refuted, if not for the reality that Prensky never did mention in any of his work that homogeneity is a digital native attribute. Rather, Prensky states that "Digital Immigrants typically have very little appreciation for these new skills that the Natives have acquired and perfected through years of interaction and practice" [1], informing us through syntax that the focus is on the end product 'the digital native'. This is the premise of the concept's advocates (see Figure 1).
It is therefore realistic to expect that, if studies are performed on students who are still in the continuum of acquiring and perfecting their skills, as illustrated in Figure 1, the empirical evidence will certainly highlight diversity in digital competence, as exactly established by several studies [27], [35], [38]. To borrow a language acquisition concept, the interlanguage theory, what the evidence portrays is the inharmonious process of pursuing digital nativeness, in a similar manner as how different language learners have varying levels of interlanguage in their pursuit of native fluency of the same target language [50]. Thus, we arrive to our second hypothesis, digital learners have diverse abilities, but as they acquire and make perfect their competence, they will develop similar skills and reach near homogeneity.

\subsection{Entertainment vs. educational purposes}

The previous two generated hypotheses (3.1. and 3.2.) are indicative of the potential existence of digital natives only when learners eventually achieve a high level of digital technology fluency brought about by immersion in an increasingly digital world. At the same time, none of the 64 articles analysed provided conclusive evidence that a single digital native learner even exists.

One common denominator shared by all 64 articles, as predetermined by the review inclusion criteria, was that they all represented the field of education [16]. Perhaps due to this constrained perspective, researchers only see learners within the scope of educational research whereby learning is juxtaposed against their use of digital technology. In other words, learners may not exhibit digital nativeness in 'learner mode', but may have already achieved digital nativeness in their use of technology for social and entertainment purposes [51][52]. Perhaps, what needs to occur is not just the learner evolving towards digital nativeness, but also the evolution of learning itself to replicate the draw of entertainment and social satisfaction [19].

It is apt to reveal that Brunei is ranked $2^{\text {nd }}$ in the world for $\mathrm{iPad}$ internet penetration [53], $1^{\text {st }}$ in Facebook usage in Asia with $62.3 \%$ as well as the $2^{\text {nd }}$ highest in Asia for Internet penetration with 78\%, one below education powerhouse South Korea who were at $82 \%$ [54]. Furthermore, a worldwide study by the International Telecommunications Union [55] revealed that $73.7 \%$ of the Bruneian youth population is digital natives, ranking Brunei as $13^{\text {th }}$ out of 180 countries in its World Digital Natives ranking. More recent reports revealed that "Brunei Darussalam has the third highest social media penetration in the world with 370,000 users, or 86 per cent of the total population, according to the new Digital in 2017 Global Overview report from We Are Social and Hotsuite" [56] and that Brunei's 
social media penetration through mobile devices is $6^{\text {th }}$ in the world [56]. All these statistics are indicative of learners immersed in a digital world.

Supporting these statistics, a recent learner profiling study performed on 147 Bruneian students found that every student owned at least an internet enabled device (a smart phone) [20] and a qualitative enquiry of their use of these internet enabled devices established that usage was predominantly for social and entertainment purposes [22]. The studies inferred that they may not have achieved digital nativeness, but they are undoubtedly much closer to fulfilling it based on the trajectory of social and entertainment use as opposed to educational use.

In this regard, they are native users of smart phone devices. Arguably, so are adults born before the 1980s who have digitally transitioned from using rotary dial telephones to haptic touch screen smart phones. As such, digital nativeness occurs not as an all-encompassing process, but in more specific occurences in tandem with the specific technologies an individual is immersed in.

Synonymous to technology immersion is the concept of 'digital worlds'. A scoping search generated 95 articles dedicated to the concept within educational research, which included further elucidations by Selwyn on the future of education in an increasingly digitised education system [18], and the increasing role of digital entertainment in education [19] - a realistic prospect that may eventually bridge the digital dissonance between technology use for learning and for entertainment purposes [5]. Digital dissonance is a term used to describe "the tension around learners' use of particular technologies, such as Web 2.0 tools and mobile phones in formal education contexts" [57].

The use of digital dissonance in differentiating between the 'social digital native' and the 'learner digital native', if such terms exist, is thus a relevant new dimension to this discourse. On one hand, the increasing use of edutainment and gamified learning for example may finally persuade casual digital natives to become digital natives of education [19]. On the other hand, the education system may contribute to further dissonance through stifling students' use of digital technology, such as the banning of phones in schools [57].

If indeed the state of complete digital nativeness is the finishing line, the end-point, to the evolution of learners in a digital world, then it can be surmised that digital dissonance acts as a barrier to achieving this state. The limited body of literature on digital dissonance has established its negative impact towards learning with technology [57] but to date there is no dedicated research on how to overcome dissonance.

The distinction between learners use of digital technology based on purpose is an interesting hypothesis in response to our question. It suggests that learners may not exhibit digital nativeness in learning, but they may be regarded as digital natives based on use of digital technology for social and entertainment purposes.

\subsection{Nativity vs. wisdom}

So far this review has analysed the digital natives theory based on the assumptions of digital nativity as an end-point to a transition process; a process of one's nativisation to digital technology. This is however in contrast to its original interpretation as a state of being born into its attributes, more specifically of being born after the 1980s. Without allowing for this flexibility of viewing nativity as a process, the debate therefore remains an either/or binary argument. In order to make the theory at least be useful in profiling learners, it must contradict its original deterministic definition.

Prensky himself has refined his standpoint on digital natives. In his update on the theory, he refers to the digital natives term as a metaphor [17], a broad generalising mechanism that liberally profiles learners into a nominal taxonomy. Although useful as a vocabulary, this term has no clear increments of measure. The International Telecommunications Union [55] in their effort to rank the digital native populations of various countries presented percentage values, but in truth these values were formulated from estimations based on various population-based factors such as a country's level of technology use [55]. No actual diagnostic tests were conducted on individuals to discern their order of digital nativeness, just numbers mathematically formulated together.

Without a defined scale or order of nativeness and what each increment of nativeness represents, the term has little value in educational research. A data collection instrument called the Digital Native Assessment Scale (DNAS) [43] has attempted to define these increment measures and the items are more indicative of nativeness being a process than a state of self; or 'digital nativisation' as opposed to 'digital natives'.

Digital nativisation is however not simply a preprogrammed or 'rewired' [58] process of maturing into nativeness. 10 years immersed in technologies of the $90 \mathrm{~s}$ is very different from 10 years immersed in the far advanced technologies that we have now. Prensky's reinvention of the theory to digital wisdom reflects this idea of a continuous attribute (wisdom) rather than a nominal attribute (nativity); of an abstract metaphor on nativisation whereby the more wisdom one acquires, the more 'native' the individual becomes [17].

At last, the digital native theory, or rather digital wisdom theory, reflects the diversity and dynamicity of learners whose digital capacity is influenced by the digital world and its many practice (i.e. learning, 
socialising, entertainment purposes). In other words, the digital native remains the end-point of the trajectory towards complete digital fluency and that it is digital wisdom that shifts learners across the nativity continuum, constantly moving back and forth based on the everchanging digital world and its technologies.

Drawing from the studies that alluded to younger learners having a more developed digital capacity than older learners [40], [42], it can be surmised that this nativisation process is not dependent on the amount of time being immersed in the digital world. Rather, it is related to the types of digital technologies that each cohort of learners is immersed into and the wisdom to interact with them.

For example, a generation that was immersed in command laden MS-DOS would have experienced a steeper learning curve than a comparable generation immersed in plug and play iOS interface. Different technologies impart and require different amounts of wisdom, as well as different amounts of effort to acquire this wisdom.

As digital technologies develop into more refined and user-friendly instruments, the skills and knowledge to operate them also become less technical. Thus, digital nativeness is a process that is likely correlated to technology advancements. As digital technology becomes intrinsic, so too is the process of digital nativisation.

\subsection{The 'digital natives' of Brunei}

Are Brunei students digital natives? The preceding literature review systematically analysed the body of literature and suggested the first two of four hypotheses (3.1. and 3.2.) as probable response to the question. It did not intend to deconstruct the digital native theory, nor take it as the absolute explanation of the phenomenon. Rather, the preceding review scrutinised the digital native theory for any inferred truth. After all, it is indeed daunting for a country such as Brunei to face the prospect of dealing with a new generation of learners who have new attitudes and aptitudes [59], rely heavily on technology [43], are more open, liberal [34], [60] and confident with the Internet [60] and are overall better multitaskers [61]. Prensky and Berry hypothesized that they have changed or been rewired, inasmuch as their brains "likely to be physically different as a result of the digital input they received when growing up" [62].

As shared earlier through various statistical measures, Bruneian learners are attuned to digital technologies for social media and entertainment purposes. The statistics among other overly impressive data has resulted in a self-professed conclusion that Bruneian youths are without doubt digital natives. This may be partly true, as there is enough statistical evidence to support digital nativeness based on non-learning purposes.

In terms of the digital native 'learner' however, the digital dissonance in the Brunei learner population is still too chaotic because of the digital diversity in the population [20], [22] and the yet unidentified digital dissonance preventing learners from effectively transferring their digital skills to their learning. Thus, the decision of certain agencies in juxtaposing the digital native theory against the existing observable phenomenon of learners effortlessly using digital technology is perhaps misinformed but is currently the best fit for purpose.

On the other hand, the review has also acknowledged the empirical evidence that has been amassed to refute the theory. To this end, the paper takes the stance that this evidence might also be indicative of an 'interlanguage' towards digital nativeness.

This review has underlined four hypotheses from this same evidence into revealing that the digital native is an imminent outcome, but is ahead of its time; that the digital native involves a process not experienced by one generation in unison, but in current dissonance experienced by generations attached to the advancements of technology, and more recently the Internet; that a learner can be a digital native as a social user of technology but not as a learner; and that digital native is a diversely ephemeral outcome from acquiring wisdom to using new and emerging technologies. These four hypotheses are indicative that Brunei learners, and likely any learner, in this current digital world, are not digital natives. However, in an increasingly digital world, they are in constant pursuit of digital nativisation to prevent from being left behind.

\subsection{Future discourse on the digital natives}

For the digital natives theory, it was fit for purpose at the time when simplicity was needed in describing the new generation of digitally savvy individuals, a generation that prior to 2001 had no nomenclature in a society accustomed to naming its generations with overarching terms, viz. Lost Generation, G.I. Generation, Silent Generation, Thirteenth, Millenial Baby Boomers, etc. [63].

However, because of how the theory was perceived as deterministic as a profiling mechanism for learner populations that are undeniably heterogeneous in their dispositions and dynamic in how they evolve in tandem with advancements in technology, the term eventually fell out of fashion. Eventually, without the evidence for digital natives after 17 years, it is unlikely to be used further as a valid profiling taxonomy for digital learners when there are more reliable and comprehensive models. Regardless, this extended literature review has refined the answers to the digital nativeness of our 
undeniably digitally predisposed Bruneian learners into the four hypotheses.

Hypothesis 1: more digital natives will exist with increased technology immersion.

Hypothesis 2: digital learners have diverse abilities, but as they acquire and make perfect their competence, they will develop similar skills and reach their homogeneity.

Hypothesis 3: learners may not exhibit digital nativeness in learning, but they may be regarded as digital natives based on use of digital technology for social and entertainment purposes.

Hypothesis 4: digital nativeness is a process that is likely correlated to technology advancements. As digital technology becomes intrinsic, so too is the process of digital nativisation.

There are at least two ways forward on what to do with these four hypotheses. The first recommendation is to conduct studies that test these hypotheses in isolation. For example, Hypothesis 1 may be measured in practice through a longitudinal tracer study, on how advancement in the technology owned (e.g. smart phones) contributes to improved digital literacy. Another is a comparative study of digital skills employed between learning and entertainment purposes as per Hypothesis 3; to explore if digital dissonance is indeed more influential in learning contexts. These are mere suggestions on the way forward to making these hypotheses useful for educational research.

The second recommendation is to regard these four hypotheses as the start of a digital learner manifesto. Taking inspiration from Bayne and Ross's online teaching manifesto [64], these hypotheses on digital learners, not necessarily digital natives but learners in the trajectory towards digital nativeness, may become a useful living document that redefines learners as technologies develop and emerge in the future; as digital natives seeking digital nativeness in learning, as digital learners, or simply as learners living in an absolute digital world.

\section{Conclusion}

As concluded in the preceding literature review, the experience of a 5 year old growing up in tandem with a Windows 95 desktop is not comparable to the experience of a 5 year old growing up with the fluid haptic technologies of 2013. Thus, being critical on the apparent generation misnomer is unjust when the digital native is seemingly more ascribed to the symbiotic relationship of a generation and the immersion of technologies that exist prior and during that generation. Only when these two independent variables converge, and mastery is achieved, can these digital learners be considered digital natives.

For Brunei, this is a conundrum because our learners exhibit near homogeneous digital nativeness in the social and entertainment use of technology, yet their dispositions to use technology in learning exhibit diverse levels of nativeness stretching across the two extremes of digital native and digital immigrant continuous spectrum (not nominal binary).

The preceding literature review suggests that they are digital learners in pursuit of nativeness in an increasingly technology-laden world. Based on this new extended discussion with the inclusion of digital wisdom, digital dissonance and digital world, it is indicative that nativeness is not a one-way street. Rather, nativeness is a continuum that allows us to trace the dynamic learners move back and forth from being immigrants to being natives depending on the technology developments in the digital world.

\section{References}

[1] M. Prensky, "Digital natives, digital immigrants Part 1", On the horizon, 9(5), 2001, pp. 1-6.

[2] M. B. J. Bowe, and D. Y. Wohn, "Are there generational differences?: social media use and perceived shared reality", Proceedings of the 2015 International Conference on Social Media and Society, 2015, ACM, p. 17.

[3] G. E. Jacobs, J. Castek., A. Pizzolato, S. Reder, and K. Pendell, "Production and consumption", Journal of Adolescent \& Adult Literacy, 57(8), 2014, pp. 624-627.

[4] T. C. Reeves, and J. Herrington, "Authentic tasks: the key to harnessing the drive to", Looking toward the Future of Technology-Enhanced Education: Ubiquitous Learning and the Digital Native, 2009, pp. 205-220.

[5] T. Ryberg and L. Dirckinck-Holmfeld, "Analysing digital literacy in action: A case study of a problem oriented learning process", In Sharpe, R., Beetham, H. and de Freitas, S. (eds.) Rethinking Learning for a Digital Age: How Learners are Shaping their own Experiences, 2010, New York, Routledge, pp. 170-183.*

[6] S. A. Long, "Digital Natives: If you aren't one, get to know one", New Library World, 106(3/4), 2005, pp. 187189.

[7] T. VanSlyke, "Digital natives, digital immigrants: some thoughs from the generation gap", The technology source, 7(3), 2003.

[8] H. Stucker, "Digital 'natives' are growing restless", School Library Journal, 51(6), 2005, pp. 9-10.

[9] O. Clark, "Engaging the digital natives in learning", Primary \& Middle Years Educator, 3(3), 2005, pp. 20-25.

[10] N. Aripin, “Teaching 'Digital Natives' in $21^{\text {st }}$ Century”, The Brunei Times, 23 October 2008.

[11] R. H. A. Bakar, "HM: We need a teaching standard". The Brunei Times, 6 November 2008. 
[12] Ministry of Education, National Education System for the $21^{\text {st }}$ Century Handbook, Curriculum Development Department, Brunei 2013.

[13] H. Roslan, "Blueprint for ICT Education launched". The Brunei Times, 29 July 2010.

[14] S. Bennett, "Digital natives", In Yan. Z. (ed.) Encyclopedia of cyber behavior, IGI Global, United States, 2012, pp.212-219.

[15] S. Bennett, K. Maton, and L. Kervin, "The "digital natives' debate: A critical review of the evidence", British Journal of Educational Technology, 39(5), 2008, 775-786.

[16] P. S. P. Omarali, "In search of the fabled digital natives: A literature review based on Brunei Darussalam's digital natives population", Proceedings of the the World Congress on Education, 2017, Infonomics Society, pp. 102-107.

[17] M. Prensky, "Digital wisdom and homo sapiens digital", In Thomas, M. (ed.) Deconstructing digital natives: Young people, technology and the new literacies, 2011, New York, Routledge, pp. 15-29.

[18] N. Selwyn, Education in a digital world: Global perspectives on technology and education, Routledge, London, 2012

[19] L. Jarvin, "Edutainment, games, and the future of education in a digital world", New directions for child and adolescent development, 2015(147), 2015, pp. 33-40.

[20] P. S. P. Omarali, "Investigating the effectiveness of the 'Online Learner Profiling Questionnaire' in generating a profile of learners based on learner dispositions: A pilot study”, In Volungeviciene, A., Szücs, A., and Mázár, I. (eds.) Forging new pathways of research and innovation in open and distance learning: Reaching from the roots, European Distance and E-Learning Network, Oldenburg, Germany, 2016, pp. 99-108.

[21] P. S. P. Omarali, "Designing a survey study to measure the diversity of digital learners", International Journal on Integrating Technology in Education, 6(1), 2017, pp. 9-13.

[22] P. S. P. Omarali, "Investigating the reciprocity of interviews with the 'Online Learner Profiling Questionnaire' as an instrument of triangulation and indepth data acquisition: A pilot study", The Future of Education. $7^{\text {th }}$ edn. libreriauniversitaria.it Edizioni, 2017, pp. 140-143.

[23] P. S. P. Omarali and G. Motteram, "Using Pierre Bourdieu's theory of practice to holistically profile online learners", In Proceedings of the Global Educators' Conference, 1(1), Manila, Philippines, 27-29 January 2017.

[24] P. Bourdieu, Outline of a theory of practice, Cambridge, Cambridge University Press, 1977.

[25] Booth, A., D. Papaioannou, and A. Sutton, Systematic Approaches to a Successful Literature Review, SAGE, London, 2012.
[26] J. Palfrey, and U. Gasser, Born Digital. Understanding the First Generation of Digital Natives. rev edn. Basic Books, Philadelphia, 2008.

[27] N. Selwyn, Education and Technology. Key Issues and Debates, Continuum, London, 2011.

[28] N. Selwyn, "The digital native - myth and reality", Aslib Proceedings: New Information Perspectives, 61(4), 2009, pp.364-379.

[29] C. Jones, R. Ramanau, S. Cross, and G. Healing, "Net generation or Digital Natives: Is there a distinct new generation entering university?", Computers and Education, 54(3), 2010, pp. 722-732.

[30] G. Kennedy, K. L. Krause, K. Gray, T. Judd, S. Bennett, K. Maton, and A. Bishop, "Questioning the net generation: A collaborative project in Australian higher education", Who's learning, 2006, pp.413-417.

[31] C. Brown, and L. Czerniewicz, "Debunking the 'digital native': beyond digital apartheid, towards digital democracy", Journal of Computer Assisted Learning, 26(5), 2010, pp. 357-369.

[32] J. Elwood, and G. MacLean, "ICT usage and student perceptions in Cambodia and Japan", International Journal of Emerging Technologies and Society, 7(2), 2009, pp. 65-82.

[33] C. Jones, and S. Cross, "Is there a Net generation coming to university?, In ALT-C 2009", In Dreams Begins Responsibility": Choice, Evidence and Change, Manchester, UK, 8-10 September 2009, pp.10-20.

[34] R. Rettie, "Net generation culture", Journal of Electronic Commerce Research, 3(4), 2002, pp. 254-264.

[35] Y. Li, and M. Ranieri, "Are 'digital natives' really digitally competent? - A study on Chinese teenagers", British Journal of Educational Technology, 41(6), 2010, pp. 1029-1042.

[36] G. Kennedy, T. Judd, B. Dalgarno, and J. Waycott, "Beyond natives and immigrants: exploring types of net generation students", Journal of Computer Assisted Learning, 26(5), 2010, pp. 332-343.

[37] H. Thinyane, "Are digital natives a world-wide phenomenon? An investigation into South African first year students' use and experience with technology", Computers and Education, 55(1), 2010, pp. 406-414.

[38] P. Thompson, "How digital native learners describe themselves", Education and Information Technologies, November 2013.

[39] G. Kennedy, B. Dalgarno, K. Gray, T. Judd, J. Waycott, S. Bennett, and A. Churchward, "The net generation are not big users of Web 2.0 technologies: Preliminary findings", ICT: Providing choices for learners and learning. Proceedings ascilite Singapore, 2007, pp. 517-525. 
[40] J. Sánchez, A. Salinas, D. Contreras, and E. Meyer, "Does the new digital generation of learners exist? A qualitative study", British Journal of Educational Technology, 42(4), 2011, pp. 543-556.

[41] N. Ramdhani, and W. Wiradhany, "Indonesian Digital Natives", In Information and Communication Technology, Springer, Berlin Heidelberg, 2013, pp. 152161.

[42] S. Zimic, "Not so 'techno-savvy': Challenging the stereotypical images of the 'Net generation"', Digital Culture and Education, 1(2), 2009, pp. 129-144.

[43] K. Lloyd, and P. Devine, "The Net Generation”, Access Research Knowledge No.62, 2009.

[44] R. Eynon, "Supporting the 'Digital Natives': What is the Role of Schools?", In Proceedings of the $7^{\text {th }}$ International Conference on Networked Learning, Alborg, Denmark, 3-4 May 2010, pp. 851-858.

[45] T. Teo, "An initial development and validation of a Digital Natives Assessment Scale (DNAS)", Computers and Education, 67, 2013, pp. 51-57.

[46] International Telecommunication Union, Global ICT Developments 2001-2013, 2013.

[47] Bureau of Labor Statistics, Computer ownership up sharply in the 1990s on the Internet, 1999.

[48] J. Schmitt, and J. Wadsworth, Give PC's a chance: personal computer ownership and the digital divide in the United States and Great Britain, Centre for Economic Performance, London School of Economics and Political Science, London, 2002.

[49] C. J. Moschovitis, H. Poole, and T. M. Senft, History of the Internet: A Chronology, 1843 to the Present. AB C-CLIO Incorporated, 1999.

[50] E. Tarone, "On the Variability of Interlanguage Systems", Applied linguistics, 4(2), 1983, pp.142-164.

[51] D. L. Williams, V. L. Crittenden, T. Keo, and P. McCarty, "The use of social media: an exploratory study of usage among digital natives", Journal of Public Affairs, 12(2), 2012, pp. 127-136.

[52] T. Correa, "Digital skills and social media use: How Internet skills are related to different types of Facebook use among 'digital natives"', Information, Communication \& Society, 19(8), 2016, pp. 1095-1107.

[53] Pingdom, The 10 most iPad friendly countries in the world, 2012.

[54] Internet World Stats, Internet World Stats Usage and Population Statistics, n.d.

[55] International Telecommunication Union, Measuring the Information Society 2013. ITU, Geneva, 2013.
[56] A. Othman, "Brunei $3^{\text {rd }}$ largest social media user in the world", Borneo Bulletin, 28 January 2017.

[57] W. Clark, K. Logan, R. Luckin, A. Mee, and M. Oliver, "Beyond Web 2.0: Mapping the technology landscapes of young learners", Journal of Computer Assisted Learning, 25(1), 2009, pp. 56-69.

[58] M. Prensky, and B. D. Berry, “'Do they really think differently",, On the horizon, 9(6), 2001, pp. 1-9.

[59] D. Oblinger, "Boomers Gen-Xers Millennials", EDUCAUSE review, 500(4), 2003, pp. 3747.

[60] L. Leung, "Impacts of Net-generation attributes, seductive properties of the Internet, and gratificationsobtained on Internet use", Telematics and Informatics, 20(2), 2003, pp.107-129.

[61] T. Uğraş, and S. Gülseçen, "Multitasking: Digital Natives' Interaction with New Media", In Engineering Psychology and Cognitive Ergonomics. Understanding Human Cognition, Springer, Berlin Heidelberg, 2013, pp.94-103.

[62] M. Prensky, and B. D. Berry, “'Do they really think differently", On the horizon, 9(6), 2001, pp. 1-9.

[63] S. Keeling, "Advising the millenial generation", NACADA Journal, 23(1-2), 2003, pp. 30-36.

[64] S. Bayne, and J. Ross, "Manifesto redux: Making a teaching philosophy from networked learning research", In Cranmer, S., Dohn, N. B., de Laat, M., Ryberg, T., and Sime, J. A. (eds.) Proceedings of the $10^{\text {th }}$ International Conference on Networked Learning 2016, Networked Learning Conference, 2016, pp. 120-128. 